\title{
Assessing the Potential for Pathogen Transfer from Grassland Solls to Surface Waters
}

\author{
D. M. Oliver,1,2 C. D. Clegg, 1 P. M. Haygarth 1 and A. L. Heathwaite 3 \\ 1Soil Science and Environmental Quality Team, North Wyke Research Station, \\ Okehampton, Devon EX20 2SB, United Kingdom \\ 2Department of Geography, University of Sheffield, Sheffield S10 2TN, \\ United Kingdom \\ ${ }_{3}$ Centre for Sustainable Water Management, \\ The Lancaster Environmental Centre, Lancaster University, \\ Lancaster LA1 4YQ, United Kingdom
}

\author{
I. Introduction \\ II. Pathogens in Livestock Wastes \\ A. Bacteria \\ B. Protozoa \\ C. Viruses \\ III. Detection and Enumeration Techniques \\ A. Culture-Based Methods \\ B. Direct Counting Approaches \\ C. Molecular Methods \\ IV. Transfer from Soil to Water \\ A. Lateral Surface Pathways \\ B. Matrix Flows \\ C. Soil Retention Effects \\ D. Bypass Mechanisms in Soil \\ E. Movement via Growth and Motility \\ F. The Role of Soil Mesofauna \\ V. The Role of Colloids in Facilitating Transfer \\ VI. Factors Affecting Survival \\ A. Survival in Livestock Wastes \\ B. Survival in Soil \\ C. Survival in Water \\ VII. Concluding Remarks \\ References
}

Contamination of surface waters with pathogenic micro-organisms is an area of growing importance in the context of diffuse agricultural pollution. Hydrological pathways linking farmed land to receiving waters may operate as vectors of disease transmission. Runoff from grassland systems may be particularly important. In this chapter, we synthesize and evaluate recent and contextual studies relating to the issue. The chapter is necessarily wide ranging and interdisciplinary but we have focused largely on the hydrological, soil-based, and microbiological perspectives. The potential for pathogen presence in livestock wastes is demonstrated through prevalence studies, and subsequent loading of grasslands with contaminated wastes generates a potential surface store of pathogens. These microbes may then be transferred to the wider environment when source and transport drivers are combined in, for example, precipitation events. The delivery of contaminated agricultural drainage waters into first order streams may impact the quality and ecological balance of watercourses if the micro-organisms of concern are still viable. This chapter evaluates both die-off and transfer processes operating from source through to the end point receptors in surface waters. Gaps in knowledge are identified and 
appear to be due to the contribution of heterogeneity and hydrological complexity of agricultural catchments and the complications of prevalence data derived via a range of methodologies. 